\title{
Immigrant Family Financial and Relationship Stress From the COVID-19 Pandemic
}

\author{
Catherine A. Solheim ${ }^{1} \cdot$ Jaime Ballard ${ }^{1} \cdot$ Nusroon Fatiha ${ }^{1} \cdot$ Zamzam Dini $^{1} \cdot$ Gretchen Buchanan $^{1} \cdot$ Soyoul Song ${ }^{1}$
}

Accepted: 15 December 2021 / Published online: 23 February 2022

This is a U.S. government work and not under copyright protection in the U.S.; foreign copyright protection may apply 2022

\begin{abstract}
We tend to overlook immigrant families in policy and program discussions related to the COVID-19 pandemic, yet they are some of the most vulnerable to the effects of this continuing crisis. This study examined the impact of the COVID-19 pandemic on immigrant families in an upper Midwest state. We interviewed 19 human and social service providers from agencies serving Somali, Latinx, and Karen (refugees from Burma/Myanmar) immigrant families between June and August 2020. Results analyzed for this paper focused on responses to questions asked about COVID-19-related financial and familial stress, and coping resources and constraints that providers were observing with their immigrant clients. Guided by the Family Adjustment and Adaptation Response Model (Patterson, 1988), we identified a pile-up of financial and relationship stressors including employment, housing, and family relationship strains, and resource access constraints. We found that job loss in already financially vulnerable immigrant families was particularly impactful. Housing insecurity soon followed. Immigrant families also faced significant constraints to resource access including lack of documentation, fear of making a mistake, language barriers, and lack of technology skills. We identified family and community resources that families used to meet demands, coping strategies, and glimmers of resilience. As we near the end of the pandemic, we urge family researchers to monitor long-term effects of the crisis on immigrant families. Findings can inform the creation of programs and policies that address immigrant family needs for resources and culturally relevant services to support their financial recovery post-COVID.
\end{abstract}

Keywords Immigrant families $\cdot$ COVID-19 $\cdot$ Stress and coping $\cdot$ Immigrant family finances $\cdot$ Financial wellbeing

\section{Introduction}

Although Covid-19 has affected all U.S. families, immigrant families are particularly vulnerable to stressors induced or heightened by the pandemic. Discussions about policies and programs that support family well-being in COVID's wake tend to overlook this population. However, ignoring their unique needs could have long-term consequences for the US; approximately $56 \%$ of all immigrants work in industries that are vital to the U.S. economy, e.g., food services, health care, social assistance, and manufacturing (Kosten, 2018). The

This is one of several papers published togetherin Journal of Family and Economic Issues on the "Special Issue onthe Social and Economic Impact of Covid-19 on Family Functioningand Well-Being".

Catherine A. Solheim

csolheim@umn.edu

1 Department of Family Social Science, University of Minnesota, Minneapolis, USA
COVID-19 workforce is especially dependent on immigrant workers; $69 \%$ of all immigrants and $74 \%$ of undocumented workers in the U.S. workforce are essential workers (Kerwin \& Warren, 2020).

Mass stressors disproportionality affect ethnic minorities (Clark et al., 2020; Galea et al., 2002). Immigrants' past trauma exposure during migration (and displacement experiences for refugees) may result in anxiety, depression, and post-traumatic stress symptoms (Mattar \& Piwowarczyk, 2020). Current rhetoric that blames immigrants for the COVID-19 pandemic and even hate crimes against them (Calma, 2020; Levine, 2020) leave them vulnerable to re-traumatization.

Additionally, immigrant families primarily work in a labor force stratum that does not provide living wages, benefits, or job security (Clark et al., 2020; U.S. Bureau of Labor Statistics, 2018a; 2020). Financial difficulties put families at risk for poor health and relationship violence (van Gelder et al., 2020; Yoshikawa et al., 2020). Moreover, jobs typically held by immigrants do not have telecommuting 
flexibility. Pre-pandemic data show that only $16.2 \%$ of Hispanic workers' jobs allowed them to work from home compared to $31.4 \%$ of non-Hispanic workers (Gil et al., 2020; U.S. Bureau of Labor Statistics, 2018b).

According to the Family Adjustment and Adaptation Response (FAAR) Model (Patterson, 1988), families use their capabilities and resources to respond to stressors or demands that arise from a crisis, currently, the COVID-19 pandemic. If the crisis continues and demands overwhelm the family, heightened and prolonged stress affects the physical and mental health and relational wellbeing of family members. Although immigrant families have demonstrated remarkable resilience through their migration and adaptation to America, they also have significant vulnerabilities that expose them to financial and relational wellbeing risk in the wake of the pandemic.

Immigrants are in all socio-economic strata of the U.S. demographic profile, depending on the nature of their migration path, their education, and the length of time they have lived in the US, etc. The focus of this paper is on a subset of the immigrant population who came to the US to seek economic opportunity, safety, and security, and find themselves struggling financially to meet daily living needs during the first several years in their new homeland. Immigrants with refugee status receive short-term government financial support; other immigrants may rely on previously resettled family members for assistance. Non-profit organizations and faith communities provide social support and some non-formal financial assistance when possible. The reality is that it takes substantial time to achieve economic self-sufficiency (O'Donnell et al., 2020; Tran \& Lara-Garcia, 2020).

An unforeseen crisis like the COVID-19 pandemic disproportionately affects immigrant families due to their already vulnerable financial situations; these families also embody strengths that allow them to weather these storms, though not without long-term impacts. It is therefore imperative that we systematically document how immigrant families are managing during the COVID-19 crisis. In the following section, we highlight immigrant family strengths and select economic realities exacerbated by the pandemic.

\section{Immigrant Family Strengths and Economic Realities Pre-COVID-19}

\section{Family Strengths}

Immigrant families, though very diverse, share some common characteristics that promote wellbeing. Generally, they develop and nurture family and community social capital to which they contribute and from which they draw both tangible and intangible resources. For example, they may share care responsibilities for children and elders; they may employ lending circles among trusted friends to save for large purchases; they may share food and clothing within and among families (e.g., see Ebaugh \& Curry, 2000; Zhou $\&$ Xiong, 2005). Immgrant families are more likely than native-born families to live in multigenerational households and to share resources such as phones and cars with one another (Smets, 2018).

These characteristics are considered unique to immigrant families in that much of American culture has institutionalized these behaviors, such as enlisting daycare organizations and nursing homes for child- and elder-care, banks and credit institutions for loans (versus non-formal communitybased lending circles), and government transfers such as the Supplemental Nutrition Assistance Program (SNAP) for food needs (versus community-based food sharing). The community social capital gained through directly engaging in these activities with trusted givers and receivers develops strong and enduring relationships that, in the dominant culture, primarily involve serial exchanges with neutral third parties. Marginalized immigrant families need to develop deep social capital to draw upon as they navigate unfamiliar and sometimes oppressive systems (Carson, 2009).

\section{Jobs and Income}

Immigrants comprised over $17 \%$ of the U.S. labor force in 2019, almost half of which was Hispanic and one-quarter was Asian (U.S. Bureau of Labor Statistics, 2018a; 2020). They were more likely than were native-born workers to hold service jobs (22.5\%); natural resources, construction, and maintenance jobs (13.4\%); and production, transportation, and material moving jobs (14.7\%). Immigrants' (foreign-born workers) median wages $(\$ 800)$ were $85 \%$ of those earned by native-born workers (\$941).

\section{Dependents}

Immigrant families tend to be larger than families headed by U.S.-born natives and households tend to be a mix of nuclear and extended family members (Burr et al., 2010), which increases the demand on limited incomes. Immigrants are more likely than native-born Americans to live in a multigenerational household, $24.6 \%$ and $15.6 \%$ respectively, with increasingly three or more generations under one roof (Pew Research Center, 2011). U.S. population-based research indicates children in larger families are more likely to live in poverty (Congressional Research Service, 2020).

\section{Remittances}

A study by Wilmsen (2013) found that immigrant participants sent $19-65 \%$ of their income abroad, often sacrificing necessities for their U.S.-based families to support 
struggling family members back home. Sanon et al. (2016) found adverse health outcomes for remitting immigrants; they worked longer hours, tended to forego rest, and reported depression and/or anxiety, which led to poor management of their hypertension.

\section{Housing}

Limited incomes and immigrants' larger than average households make finding safe and adequate housing difficult (Burr et al., 2010). As a result, immigrant families are likely to live in overcrowded conditions and may forgo home quality and neighborhood safety to meet family needs (Dearborn, 2008).

Immigrants' documentation status can also affect housing location and quality. Studies have found that undocumented immigrants live in poorer quality, overcrowded housing and face more housing challenges than do documented immigrants and native-born renters (Hall \& Greenman, 2013; McConnell, 2017). Once housing is secured, unscrupulous landlords may take advantage of immigrants who do not know their legal rights and protections (Byrne et al., 2018).

Desmond (2018) found that more than half of low-income renters are highly rent-burdened, meaning they pay more than $50 \%$ of their income on rent. Immigrant families bear more rent-burden than U.S.-native families (McConnell, 2013); Black and Hispanic renters are disproportionately affected and undocumented Latinx immigrants experience $41 \%$ higher odds of rent burden than do documented Latino immigrants (McConnell, 2013). Rent-burdened families may cut back on necessary expenses such as food or medicine to pay their rent, causing cascading negative effects on the family's finances, health, and wellbeing (McCue, 2018).

\section{Macro-Environment Factors}

Systemic, structural factors also affect immigrant family wellbeing and resilience (Vesely et al., 2017), some directly relating to factors previously discussed-the lack of affordable, safe housing to accommodate large, multi-generational families, and jobs that pay less than a livable wage and provide no health or sick leave benefits. Additionally, we must consider the emotional and psychological effects of migration trauma exposure, the fear of deportation, and the social stigma that surrounds immigration. This puts immigrants at increased risk for health problems (Bhopal, 2020; Cholera et al., 2020; Garcini et al., 2020; Page et al., 2020), and they may be deterred from accessing critical resources and services for which their U.S.-born citizen children qualify (Vesely et al., 2017).

\section{The Present Study}

Two overarching aims focused our research project. First, we aimed to conduct a rapid assessment study to identify immigrant families' unique relational and financial stressors, and barriers to access resources, and bring them to the forefront of policy and program discussions as the pandemic continued. Second, we aimed to amplify immigrant families' unique relational and financial resources that would contribute to the growing literature on immigrant family strengths.

\section{Materials and Methods}

\section{Study Design}

This was a qualitative study designed to gather data efficiently and effectively to learn about the impacts of COVID19 on immigrant family finances and relationships as the pandemic was occurring. Our aim was to interview human service providers who served immigrant communities in both urban and rural areas of the state to capture their perspectives about most pressing stressors faced by immigrant families and learn about the resources families were using to cope with those stressors. We chose to focus on providers who served clients from three of the largest immigrant communities that continue to receive new families in an upper Midwest state: Latinx, Somali, and Karen.

\section{Immigrant Community Groups}

Although a comprehensive description of each immigrant group is impossible due to this paper's scope, it is important to know something about each group to provide a basic context for the experiences that are shared by the service providers.

Latinx Immigrants Latinx families are migrants seeking better jobs, education, or safe environments for their families; their community receives a continual influx of new arrivals. Latinx families first arrived as migrant farm workers in the 1800s and have been a major presence for many decades (Eisenberg et al., 2019). Immigrants, primarily of Mexican origin (72\% in 2014) (Culture Care Connection, n.d.), have been drawn to the state for job opportunities in food processing, construction, and manufacturing. Their long-term presence in the state leads to a complex mixture of stable, successful Latinx families and those who are recent immigrants who struggle with high rates of poverty and lack access to healthcare. Latinx cultural strengths include a sense of loyalty among extended family and their larger kin network and a deep respect for others, especially elders and those in positions of authority (Culture Care Connection, n.d.). 
Somali Immigrants Somalis began arriving as refugees in large numbers in the 1990s, after the onset of their country's civil war (Abdi, 2014). They are predominantly of one culture, language, and religion (Islam), though they are divided socially and politically by clans along paternal lineage (Centers for Disease Control [CDC], n.d.). The war devastated Somali infrastructure including schools, so literacy of first-generation immigrants is quite low; approximately $50 \%$ for men and $26 \%$ for women (CDC, n.d.). Somali families faced discrimination in their new homeland, especially after 9-11, when some Americans reacted with fear of a generalized Middle Eastern and/or Muslim 'other', which caused Somalis to be concerned for their personal safety (Ali, 2011). Somali family strengths include a strong sense of kinship and support from immediate and extended family, values of interdependence and sharing resources, and a strong oral tradition and value of hands-on learning (Center for Advanced Studies in Child Welfare, 2014).

Karen Immigrants Karen refugees are a minority population from the Karen State in Burma. There are also small numbers of Karenni and Mon refugees, also from Burma near the Karen State. These three groups of people were forced to flee to nearby Thailand refugee camps to escape ethnic persecution. They began arriving in the US in 2002 (Karen Organization of Minnesota, n.d.; Power et al., 2010) and continued until the U.S. restrictive refugee resettlement policy was implemented in 2017. Most Karen in the state in which this research was conducted identify with a Christian faith tradition, though there are also Buddhist, Muslim, and Animist Karen. Karen family strengths include values of cooperation, humility, and education, as well as resourcefulness and craftsmanship such as in weaving traditional clothing (Ranard \& Barron, 2007). Given their relatively recent arrival, Karen language and culturally adapted services are still being developed.

It is also important to mention that we did not include another large immigrant community in the state, namely the Hmong community. Families first arrived post-Vietnam War and few new Hmong refugee families have arrived in the state since 2004 when the last Thai camp, Wat Tham Krabok, was closed. Although many families still struggle, the community is well-established, and we chose to focus in this study on newly arrived immigrant families.

\section{Study Procedures}

We sent an introductory email to agencies who served immigrants from the three aforementioned groups that were identified from the research team's network of community partners, to request that they ask their staff if they would be willing to be interviewed for the study. Due to the need to gather data expeditiously, we did not have time to build relationships with new partners. We note that immigrant communities are likely to have experienced institutional betrayal and to be slow to trust institutions (Vesely et al., 2017). Therefore, we made the decision to recruit from within our existing network. If staff were interested, their contact information was shared with the research team, who contacted them, described the study in more depth, and if they agreed to participate, set up a time for a Zoom-based interview. The study was deemed exempt by the University's human subjects' office, therefore, no consenting process was necessary.

Two research team members conducted Zoom-based semi-structured interviews between June and August 2020 with 19 health and human service providers who had worked with immigrant communities for 7 months to 29 years ( $M=6.32$ years, $S D=8.66$ ). Eight providers served Somali communities, six served Latinx communities, three served Karen communities, and two served multiple groups. Ten providers were located in urban areas, and nine were in rural locations. We thanked participants with a $\$ 100$ e-gift card.

We asked agency staff to describe their generalized knowledge about the experiences of the immigrant families they had been serving since the onset of COVID-19, and importantly, their perceptions of these families' stressors, coping strategies, and overall well-being. The interview protocol addressed six broad domains including (1) jobs, (2) housing, (3) food, (4) health and health care access, (5) family relationships, and (6) coping strategies. This paper focuses on responses related to financial and familial stress and coping resources.

\section{Analysis}

We used an inductive content analysis strategy to analyze interview data, first conducting open coding and writing headings to describe the content (Elo \& Kyngäs, 2007; Hsieh $\&$ Shannon, 2005). Two researchers read all the transcripts. Then they coded half an interview together to arrive at initial consensus, assigning as many codes as necessary to describe the narratives' content. They iteratively coded small batches of interviews, then met together to review questions, establish further consensus, and code a small section together, before coding another batch independently. After coding five interviews, they grouped the lists of codes into higher- and lower-order groups. Then the full research team met to discuss the themes to determine if similarly coded sections of text held the same meaning for both coders (Elo \& Kyngäs, 2008).

Based on our goal of reporting shared experiences across families, we decided to retain a code only if it appeared in at least two distinct interviews. We note that this was an analytic decision and does not discount the significance of an experience that was reported only once. We also acknowledge that 
our limited sample may have prevented us from hearing an experience more than once. However, within the purpose and scope of this paper, we report results that reflect experiences that were reported by at least two providers.

Because our goal was to get a fairly quick read on how COVID-19 was affecting immigrant families in general, and because our sample of informants was fairly small and limited to providers who served only three of the immigrant communities in the state, we report our findings in the aggregate, across immigrant groups and locations. This yields an overall picture of immigrant families' stress and coping during the early period of the COVID-19 pandemic. Subsequent analysis beyond the scope of the current paper will compare experiences by groups and location.

\section{Trustworthiness}

We employed trustworthiness criteria throughout research design, data collection, and analysis stages of our study (Morrow, 2005). We maintained an audit trail of original codes, analysis decisions, and personal memos used to document interviewer reflexivity. Two independent coders each coded a manuscript with $80 \%$ agreement to the original codes; typically, adjacent coded statements captured disputed codes. At each coding stage, we discussed areas of disagreement as a team and made adjustments. Additionally, we conducted member checks with participants to report our broad categories, check agreement with how we coded their responses, and ask what we had missed. We present all data with contextualized quotes to center the voices of participants.

\section{Results and Discussion}

Providers reported that immigrant families faced significant challenges following the onset of the pandemic, particularly job loss or unsafe working conditions and subsequent housing insecurity. They also experienced barriers such as limited language and technology literacy that affected their ability to access formal government programs. Providers reported that immigrant families and communities shared and adapted their resources, allowing many to remain relatively stable even during times of trial. In the following section, we highlight components of the FAAR Model (Patterson, 1988), namely the pile-up of stressors, resources, and coping that were prevalent among immigrant families at the onset of COVID-19.

\section{Significant Contributor to Stressor Pile-Up: Employment Strain}

\section{Job Loss}

Job loss was the primary stressor facing immigrant families, and it had cascading effects. Immigrants in the US experienced higher unemployment after COVID-19 than U.S.-born workers (Kochhar \& Bennett, 2021), and undocumented immigrants' job loss far exceeded that of both U.S.-born workers and legal immigrants (Borjas \& Cassidy, 2020). Providers reported that on average, $70 \%$ of their clients had lost their jobs. Nearly all immigrant families worked prepandemic and often multiple people from the same family held jobs. As mentioned in our introduction, immigrants frequently work in industries such as hospitality and manufacturing that have been partially to completely shut down throughout the pandemic. The pandemic exacerbated the existing stressors of insecure jobs without many benefits or protections. One provider shared:

..... there's no place to work. They just closed their restaurant. They closed everything. Those are big, big employers. Distribution got stopped, so a lot of the drivers, too, end up with no jobs. The guys that helped load and unload also ended up with no jobs.

If workers lost their jobs, it was clear from providers' narratives that their clients wanted to return to work as soon as possible. In fact, at the time of our interviews in summer 2020 , some had already gone back to work. Yet others could not find jobs in the sectors in which immigrants and refugees typically work. Another dilemma raised was that "We had participants who couldn't go back to work because their children now are at home and they don't have childcare."

Although unemployment benefits helped to mitigate the income lost from jobs, many workers were not eligible to draw unemployment compensation due to ineligibility or complications with documentation. We further explore these barriers later in our paper.

\section{Unsafe Employment Conditions}

Other immigrants were able to keep jobs. However, many felt they had no viable choice but to remain in jobs, even when doing so endangered their health and that of their families (i.e., employers not establishing or enforcing pandemicsafety guidelines such as social distancing and mask wearing in the workplace). They could continue to work to keep their family's income stream flowing or stay home to take care of their health and that of others, but consequently lose income in the short-term and perhaps their job in the longer-term. 
The fear of losing their jobs and the corresponding loss of critically needed income for their families affected how immigrant and refugee workers dealt with illness and potentially having COVID-19. Providers noted that there was little protection for workers in some workplaces and/or employees felt they had no power to resist employer demands. Employees felt pressured to go back to work, even when showing symptoms of COVID-19 or awaiting results of a COVID19 test. A provider quoted a client's explanation of their dilemma:

I've been sick for, I might have taken already 7 days of the 14 days I'm supposed to be because this started back in so and so. It's still at that stage where I'm going to lose my job if I just say I feel achy, I don't know yet. Instead of going in to get it tested and staying home. I might lose my job, so let me talk to my work first and figure out what they think. And if they tell me, then, to get tested, then I'll go get tested.

\section{Significant Contributor to Stressor Pile-up: Housing Strain}

\section{Insecure Housing}

Providers immediately linked job loss to clients' inability to pay rent and fear of losing housing. They reported that an average $38 \%$ of their clients could not afford rent or mortgage. Two providers also noted that some clients would be uncomfortable about sharing this type of information, so it is likely that the percentage of families who struggled to pay rent or feared they would lose their housing was higher.

Immigrant vulnerabilities during the pandemic also emerged in conversations about rent and discussions with their landlords. Some clients were threatened with eviction during the moratorium, despite the federal mandate that this be prohibited (CDC, 2020). A provider vividly described client-landlord interactions:

The landlord like yell at the clients to pay rent. The landlord also say things like, you need to move out by this date if you don't pay your rent. It's really painful to hear that. Because when you don't speak the language, people might take advantage of you.

\section{Bill Pile-up}

If families did not feel threatened with immediate eviction, the overwhelming thought of a significantly accruing rent bill loomed large. Although they appreciated the eviction moratorium, they knew they would need to pay all past-due rent once the moratorium ended. As one provider stated:
It's understandable that there was this opportunity from the state saying, if you cannot afford the rent, you cannot be evicted, but nothing else. Later on, it's going to pile up and if I don't have a job, the second biggest concern [after spreading COVID to family], if I don't have a job, how am I going to go back and pay? Eventually, I'm going to be evicted.

One provider underscored how important paying rent was to her immigrant clients:

And I'm sure you guys know, as far as immigrants go, paying off rent is very important to these families. Before even putting food on their plate, rent is important. Before even getting stuff for their kids, rent is important. I felt like they're being able to keep their housing status for now just because that's their mentality. Nowhere else does money go before rent.

\section{Crowded Living Conditions}

Many families moved in with other family members to prevent homelessness. One provider shared, "So the first concern was, where am I going to live. 17 families that I know have decided to move out and not renew contract and move with family members." Another provider stated, "Out of 80 families, they have 31 families that are considered homeless now because they moved with relatives". (Note: The McKinney-Vento Homelessness Assistance Act (2002) includes "sharing the housing of other persons due to loss of housing, economic hardship..." in their definition of homelessness). In addition to the strain this puts on relationships, overcrowding can lead to increased risk of spreading the coronavirus to family members (Page \& Flores-Miller, 2021).

\section{Significant Contributor to Stressor Pile-up: Family Relationship Strain}

Many families grew closer during the pandemic (described in the "Coping" section below). However, families faced several relationship stressors, including the inability to support family in their home country, small spaces and few options for outside activities, and in some cases, family violence.

There were different issues for youth who seemed to be frustrated by the constraints of COVID-19 and social isolation at a time in their development when some level of autonomy and interaction with peers is important. One provider commented:

So there's definitely - a lot of our youth right now feel like they don't have any privacy, feel like they don't have any freedom because a lot of our parents are being now more strict because-to keep each other safe. 
At-home teens presented special challenges, as a provider explained:

But also the reality is for teenagers, perhaps, they couldn't be anywhere. With the teenagers it's a little different. Now I'm at home for four months and I haven't been able to see my friends and I haven't been able to do anything. Or not about-they graduated this year from high school. And not being able to do the things that other teenagers do like graduation.

\section{Parents Exhausted by Their Children's Needs}

While children were at home, parents needed to find ways to meet all of their needs without the normal outside activities or supports. One provider described parents' dilemmas:

Because we knew that they were saying, what do I do? It's so many hours in the day. I can't just_-and I live in the third floor. I'm not in a big house. I don't have a big yard where my children can go out and run.

Parents' stressors piled up and took a toll, as a provider described, "Our parents are also exhausted because they can't find a job and their kids need X, Y, Z." This parenting toll was experienced by native-born and immigrant communities alike. However, the increased unemployment in immigrant communities significantly added to their parenting stress. Family members with better English skills were more likely to have jobs outside the home, so family members who remained at home to care for children were less able to navigate school activities or access outside resources to meet their children's needs.

\section{Inability to Support Family in the Home Country}

COVID-19 also affected transnational family members, those who remained in the home country, which in turn, affected family members in the US. A provider explained their presence in the everyday lives of immigrant families:

Back home, they work a lot because-now, we see in United States America, one of the greatest country, biggest country, it's big for everything, it's struggling with COVID-19. What do you think is going to happen in Africa, especially in Somalia that doesn't have a strong central government? So they worry a lot. They worry for their families. They worry for their loved ones. They worried for what's going to happen back there, the ones that they left. They cannot do anything for them. They cannot travel. If they travel, that requires a lot of money to spend. They worried for their health if they go there. They worried they might get infected with COVID-19. So there are so many things that they are worried about in terms of financial and health.

Immigrant families share a common experience of feeling responsible to financially support their family members living in the home country. Income loss associated with COVID-19-related job loss rendered sending remittances home nearly impossible and caused distress and strain for many immigrant families. A provider described it this way:

For the families that were able to continue that, I mean, nothing has changed in that area. But the ones that are no longer employed, they can barely keep their own roof, let alone, help another family. It's been a lot to deal with. They're having a hard time with themselves to not be able, because that overseas person that was dependent on them, they were their only source of making it to the next day or the next month. And they feel like they've failed because they can't do that.

\section{Significant Contributor to Stressor Pile-up: Constraints to Resource Access}

Government supports are available to citizens to address financial stressors, such as unemployment benefits, SNAP benefits (Supplemental Nutrition Assistance Program formerly known as Food Stamps), and the pandemic EBT (P-EBT; a temporary food benefit for children who would have received free or reduced meals if schools were open). When immigrant families were eligible and received these benefits, they were important and stabilizing resources. One provider said, "I think what we're seeing is a lot of the people that have become unemployed, if they're eligible for unemployment, some of them are doing — they're doing okay."

Generally, all limited-resource families faced barriers of limited available funds and long wait times when government-based financial support during the pandemic. However, immigrant families faced additional barriers due to a variety of cultural and contextual factors. In the following section, we amplify the interconnected barriers reported by providers.

\section{Values of Collectivism and Self-reliance}

Perhaps because many Asian-, African-, and Latinx-origin immigrants share a culture-based collective worldview that emphasizes sharing resources with others in need (Weng \& Lee, 2016), providers noted that unless they were desperate, 
their clients were hesitant to access the resources available to them. They also noted that many of these families have a sense of pride in being able to overcome many obstacles of resettlement and/or post-migration to be able to provide for their families without dependence on government assistance. COVID-19 presented new obstacles over which they had virtually no control. One provider described why she thought that the Latinx families she served weren't taking advantage of many of the government assistance programs. "They don't ask for help. They work for what they have. They're not used to asking for that kind of assistance."

\section{Documentation-Related Fears}

The ability to access resources depends on immigrants' visa status and documentation. Many government programs such as SNAP, unemployment benefits, and financial assistance are unavailable to those with work visas or without documentation. Applying for any service is scary for families without documentation, with mixed documentation within the family, or when the public charge rule may affect a families' path to citizenship, even if documentation is not a qualifying criterion for a specific service (Bernstein et al., 2020; Perreira et al., 2018; Wilson et al., 2020). A provider explained:

Part of it is fear, and part of it is because of public charge. So they fear that if they, say, you get EBT benefits for a few months, that it'll permanently eliminate their chances of ever becoming a US citizen, becoming naturalized.

A different provider shared an immigration status-related example of a barrier to resource access:

We've been trying to do the application, the emergency application of XXXX County. So, there are some families who refuse to do it, because they are also scared of what they're asking, their immigration status. So, some don't want to complete it, so they don't do it and we try to look for other options.

\section{Fear of Making a Mistake}

A few providers reported that some of their immigrant clients did not apply for benefits such as unemployment compensation, because they feared being accused of intentional fraud if they made a mistake or were determined ineligible. One provider explained:

What applying for unemployment entails, where that information goes, what will be received back whether-I think a lot of times, there's also a fear that if you apply for unemployment and you're ineligible, that you've done something wrong. Or that you've tried to somehow abuse the system.

Another provider shared the case of a client who had received unemployment compensation, but was later determined ineligible due to inadequate income. By the time the government discovered the error and asked her to repay the money, she had already sent some of it to her family overseas. A provider described the untenable situation she faced:

.... a real mental health challenge for her... she's failing there, she's failing there; she's failing here. And it's an extreme, heavy burden on her to continue on because now it's zero income for her household. And zero income for worse overseas.

\section{Lack of Technology Skills}

Providers described that many of their clients did not know how to use technologies such as smartphones or computers, that were required to set appointments, have conversations with providers, or to apply for resources or services. This discouraged families from seeking appointments and made it difficult to access resources without someone to help them through the process. One provider explained, "And then to create those accounts, you need to have an email. And some of the Karen clients don't have email. Mostly all the Karen elders, they do not have emails, so that's hard." Not surprisingly, immigrant elders found technology particularly challenging.

\section{Language Barriers}

Language was a barrier to resource access for many immigrant clients served by providers in our study. Applications for benefits and phone numbers for helplines or resource distributions typically have English or perhaps English and Spanish options. Landlords who did not speak their tenants' languages made it difficult for families to explain rent challenges or understand lease terms. A provider who struggled to connect clients to appropriate assistance helplines explained:

And then, if they're looking for other resources, they ask me and I search for them and I call them back, or I call the number, because there's a lot of numbers that only have the English option and they don't speak English.

When families struggled with complicated interactions and paperwork due to language barriers, they became frustrated and experienced great difficulty at best, or at worst, discontinued the process, thus missing access to important resources to meet their family's demands. This finding is consistent with research that English proficiency is 
associated with both health-care seeking behaviors and quality of care. In a recent study of COVID-19 testing, non-English-speaking patients were tested less frequently and had a higher burden of infection (Kim et al., 2020).

It is important to note that the language barrier perhaps undergirds many of the aforementioned barriers. Without a command of English, immigrants are likely to struggle to understand written instructions or their technical and legal implications, leading to increased fear that missteps would violate rules and lead to dire consequences. Similarly, language literacy is needed to use technology such as email, websites, and automated phone lines.

\section{Resources to Meet Stressors}

Immigrant communities have responded to COVID-19 stressors with remarkable strength and resilience. This is due in part to the family and community resources they create and share with one another. A commonly held worldview motivates immigrants from many collectivist cultures to willingly share their resources with each other in good times and in times of need (Weng \& Lee, 2016). Therefore, their stock of resources extends beyond that which they individually own. They have wealth in family and community resources, such as shared incomes and housing, faith, role flexibility, time together, and shared values of collaboration.

Immigrant-serving health and human service agencies were a key resource for families. They recognized emerging needs created by the pandemic and the barriers to accessing formal support from government and other civil society sources. They were flexible and adapted their services to meet those needs in culturally appropriate ways.

Agencies raised money to provide additional rent support for families, started community-specific resources, and provided additional support when making referrals to address language and literacy barriers. A couple of agencies noted that even when encouraged, their immigrant family clients were reluctant to use local food shelves or pantries because the groceries provided were unfamiliar and did not fit their family's food culture. In response, they raised money to create food pantries that stocked culture-specific food items for their clients. This paper's page limitations prohibit an inclusive list of resources. If interested, please see https://innovation.umn.edu/immig rant-refugee/covid-report-immigrant-families/ for the full report. In the following section, we highlight the ways immigrant families and immigrant-serving agencies used resources to cope with the stressors created or intensified by COVID-19.

\section{Coping}

\section{Sharing Family Resources}

Providers in our study reported that the first source of help for many immigrants during COVID-19 was family members who offered a place to live when income became tight (as described in the housing section). They also offered other financial support. One provider stated, "A lot of the families had to turn out to their families to loan money, too." In some cases, children's jobs became more central to the family income. As one provider described, "It's more so adult kids supporting their parents that are older and are unemployed right now."

\section{Sharing Family Role Responsibilities}

Older children, elders, and other relatives juggled childcare as a shared task with parents. One provider shared, "The older parents [are] now babysitting the children so that the parents of the younger children can continue working." Children also took on more family responsibilities to navigate the new challenges.

\section{Spending Time Together}

Although forced togetherness at home due to out-of-work parents and children's remote learning circumstances created stress for some families, which we addressed in a previous section on relationship strain, many immigrant families found that more time together was also positive. Instead of working their usual multiple jobs, unemployed immigrant parents were available to spend time with their children, who heretofore, were in school all day. An agency provider explained how immigrant families made meaning out of this newfound togetherness:

I want to say it's right down the middle of it's been very beneficial and it's been not so great. I think probably half of the patients that I'm seeing, it's been really nice to have our family together. Yeah, we can't go anywhere, but we're doing more things together. We're reading more. We're playing games. We're cooking together, or just spending time bonding, finding things to do as a family that they didn't have time to do before.

Bentley et al. (2020) similarly documented social connection as a resilience resource in the Somali community during COVID-19. 


\section{Focusing on Solidarity}

Providers shared that many families reframed their situations to find positive outcomes amidst the difficulties wrought by the pandemic. Choosing to focus on the importance and long-term benefits of social distancing improved attitudes and perceptions about the socially taxing COVID-19 restrictions. A provider explained:

They talk a lot. They have a lot of communications with their families back home. We have some clients that had plans already of returning on a vacation to visit their families before COVID started, and they just had to put it on hold. But a lot of the families are so united, and they know that we're all in this together, and it's pretty much everyone is in the same circumstances, so they keep in touch a lot.

Another provider explained how being there for one another was a way to cope with the uncertainty. "I think being there for each other, trying to help each other, trying to stay in touch with their families abroad during the crisis".

\section{Leaning on Faith}

Families may lean on their faith as a source of strength and resiliency when faced with stress (Bentley et al., 2020). A provider who works primarily with Muslim Somali families reflected:

I think historically it has been the faith communities, although during COVID, the mosques were closed to the public, similarly to any of the other religious buildings in the area. They're slowly beginning to open up at diminished capacities. They were doing a "call to prayer" yesterday. There were a few people going in, but not in the same numbers.

\section{Drawing From Community Solidarity}

Neighbors and community members also responded to needs with direct help in the form of meals, produce, and transportation. One provider commented:

I think in our community everyone supports each other like if someone is sick the other would come and help, either family or friends. I think that's the best way they support each other, or if someone has more food and the other family doesn't have food, they will share.

\section{Trusting Community Agencies}

Local non-profit agencies such as the ones represented by our provider participants are trusted resources in their communities. They became a primary locus of support, particularly for immigrants who were trying to navigate the challenges of accessing resources. One provider put it this way, "Because most of the clients, they trust our work and the job that we're doing. So they keep contacting us or they keep coming back to us with any systems for help they're needing."

\section{Family Adaptation}

Immigrant families demonstrated remarkable resilience during the pandemic. Many immigrant families became closer during this time. A provider working with youth noted:

Yeah. So a lot of my students are now working at home-sorry, now doing a distant learning at home, and so that has been a challenge, they are now most of the time. And I don't really hear of any relationship issues within the family. So I do know that they do spend more time together. A lot of my students and their family, their parents were able to go out fishing together on a weekday.

Another provider noted strengths and positive response through the challenges:

Obviously there are challenges, but the patients that we see are also very happy. It's interesting because they're dealing with all these different things. And once we have conversation with them, you realize that they're very grounded; that even though all these different things are going on, they're still very happy. And they always have a smile on their face, and they'll tell you jokes.

\section{Sometimes They Grew Closer; Sometimes They had Conflict}

Several providers described that some families with whom they worked drew closer together and others experienced more conflict. One person shared this specific example:

Right now, the relationships is good, because the father is at home, the mother is at home, children are at home. Some of them are saying it's good, and some of them are saying, We are having a problem with the kids, because before, most of the time they were in the school, and maybe the dad or the mom was in work. So, they used to see each other. Right now, it's less than before. It's two different groups. Some of them are saying, This is the best relationship that we ever had, because the dad is staying home, the mom is staying home, the kids are good. So, the whole family stays.

We note that providers were aware that family violence was still occurring in the community during COVID, and 
that it was difficult to track. Agencies offered support when families disclosed family violence.

Systemic stressors faced by immigrant families can overwhelm family relationships, leading to maladaptive coping. However, despite the build-up of stressors, many immigrant families demonstrated remarkable resilience, drawing closer together during the crisis.

\section{Limitations and Future Directions}

The focus of this research was to conduct a rapid assessment of immigrant families' financial and relational stressors, resources, and coping strategies from human service providers serving three of the largest immigrant communities in both urban and rural parts of an upper Midwestern state. The small, convenience sample of 19 providers shared their point-in-time observations and experiences with us during the early months of the COVID-19 pandemic, June through August 2020.

The decision to sample service providers to garner information about immigrant families facilitated the desired rapid assessment. However, we acknowledge that even though most of the service providers who participated in our study were immigrants themselves, they were privy only to what their clients were willing to share with them at a particular point in time. In turn, what we heard was a summation of providers' filtered perception of families' realities. We did not hear about day to day struggles of living with pandemic stressors from immigrants themselves. Moreover, our sampling decision limited our ability to generalize beyond the three selected communities and the subset of families within those communities who were served by the providers in our study.

Another limitation may stem from our request to providers to share their broad assessment of their clients' experiences. As a result, we most likely heard the most frequent challenges they heard from their interactions with clients; we may have missed less frequent experiences that nonetheless, may have been important.

\section{Future Directions}

The research team is conducting a comparative analysis of the current data to see whether stressors, resources, and coping strategies differ by immigrant community (i.e., culture) and locale (i.e., urban or rural). For example, one rural provider described struggles with transportation for medical appointments, and that buses in their rural area ran only once a day. A comparative analysis could reveal useful differences in stressors and resources based on location.

It will be important to apply a longitudinal lens to monitor long-term financial and relational effects of this global crisis on immigrant families as the pandemic ensues and eventually ends. Using the current research as a baseline assessment, the research team would like to conduct a study in which we would recruit immigrant families, conduct an initial retrospective interview to enhance our initial findings from providers and gain a deeper understanding of their financial and relational experiences to-date, and periodically follow up with them to track how they are doing.

\section{Implications}

\section{Practice}

Our interviews highlight four best practices that family-serving professionals can employ when working with immigrant families as they cope with pandemic-generated financial and relationship challenges. First, we learned that it is important to keep in mind that immigrants' financial and relationship stress reaches beyond family members living in the US; the global pandemic similarly affects their extended families abroad who perhaps have fewer resources and less support than those living in the US. In essence, those who work with immigrants must hold a comprehensive understanding of family that reflects their local and global diasporic communities. Professionals can ask clients to describe their family system, including all members they support and care for, regardless of where they are physically located. They can then assess pandemic-generated financial stress in ways that reflect immigrant families' complex demands and resources. Finally, family-serving providers can explore how identified financial stressors have affected family relationships across the family diaspora.

Second, family-serving professionals can refer clients to critical resources and services and provide technical assistance to reduce access barriers such as language literacy, technical literacy, fear of making mistakes, and documentation concerns. Rather than merely providing a phone number, providers could make the call with a client, walk families through the process, and address common questions.

Third, based on our finding that some families drew closer together during the pandemic, it is important for family professionals to explore not only the problems faced by families, but also the ways they exhibit resilience, emphasizing families' strengths as reported in this paper, such as flexible family roles and a collective or a pooled approach to resource-sharing of income, housing, and child. This can encourage families to build on their strengths as they seek solutions to their problems.

Finally, family professionals can share the aforementioned examples of resilience and family strengths with other struggling families to encourage them in their struggles. These ideas can be used more broadly to mobilize resources to meet the needs of the community, through partnering 
with mutual aid organizations and building collaboration capacity (Dominguez et al., 2020). For families that experience increased conflict in times of crisis like the current pandemic, family professionals can identify the buildup of financial stressors and consider ways to alleviate them at the same time as they are addressing the relationship conflict.

\section{Policy}

It was clear from providers' interviews that housing was by far the highest cost-burden for immigrant families and the fear of losing housing created the most stress. Study findings reemphasize the need for family-serving professionals to advocate for increasing the availability of safe and affordable housing, especially for larger, extended families as are fairly commonly found among immigrant populations.

Our conversations with human service providers also highlighted their own importance as a critical, culturallyrelevant, and trusted safety net for immigrant families. As immigrants themselves in most cases, providers are often the primary liaisons with government programs, services, and resources needed to survive in times of crisis. Familyserving professionals can advocate for adequate funding for staff and programming in mutual aid organizations and immigrant-serving agencies so that they are able to offer the culturally relevant programs and services that are critically needed.

\section{Conclusion}

This pandemic has significantly affected the economic realities of immigrant families. Investing in their recovery is critical; the success of the U.S. economy depends on their contributions. Our rapid assessment of 19 human service providers revealed that the immigrant families they served confronted a unique pile-up of stressors in the wake of the COVID-19 pandemic. They simultaneously experienced unique barriers to resources they needed to cope with those stressors. Further, providers reported that these families showed strength and resilience by leaning on each other, their communities, and local agencies. We can use this baseline information to inform continued monitoring. Moreover, we can share what we learned to inform the development of culturally relevant policies and programs that address evolving needs to ensure that immigrant families can thrive when we reach some new state of normalcy.

Funding This work was supported by a grant from the Department of Family Social Science, University of Minnesota.

\section{Declarations}

Conflict of interest The authors have no relevant financial or non-financial interests to disclose. The authors have no conflicts of interest to declare that are relevant the contest of this article. All authors certify that they have no affiliations with or involvement in any organization or entity with any financial interest or non-financial interest in the subject matter or materials discussed in this manuscript. The authors have no financial or propriety interests in any material discussed in this article.

Consent to participate Based on the evaluation of the MN IRB, participants were not required to provide consent; however, all participation was strictly voluntary.

Ethical approval Immigrant Family Stressors During COVID-19, STUDY00009994, was assigned a determination of Not Human Research by the University of Minnesota Institutional Review Board on 6.11.20.

Availability of data and material Not applicable.

\section{References}

Abdi, C. M. (2014). Threatened identities and gendered opportunities: Somali migration to America. Signs: Journal of Women in Culture and Society, 39(2), 459-483. https://doi.org/10.1086/673380

Ali, I. (2011). Staying off the bottom of the melting pot: Somali refugees respond to a changing U.S. immigration climate. Bidhaan: An International Journal of Somali Studies, 9(11). https://digit alcommons.macalester.edu/bildhaan/vol9/iss1/11

Bernstein, H., González, J., Gonzalez, D., \& Jagannath, J. (2020). Immigrant-serving organizations' perspectives on the COVID19 crisis. Urban Institute. Retrieved from https://www.urban.org/ sites/default/files/publication/102775/immigrant-serving-organ izations-on-the-covid-19-crisis_0_0.pdf

Bentley, J. A., Mohamed, F., Feeny, N., Ahmed, L. B., Musa, K., Tubeec, A. M., \& Zoellner, L. (2020). Local to global: Somali perspectives on faith, community, and resilience in response to COVID-19. Psychological Trauma: Theory, Research, Practice, and Policy, 12, S261-S263. https://doi.org/10.1037/TRA0000854

Bhopal, R. S. (2020). COVID-19: Immense necessity and challenges in meeting the needs of minorities, especially asylum seekers and undocumented migrants. Public Health, 182(January), 161-162. https://doi.org/10.1016/j.puhe.2020.04.010

Borjas, G. J. \& Cassidy, H. (2020). The adverse effects of the COVID19 labor market shock on immigrant employment. Retrieved from: https://scholar.harvard.edu/files/gborjas/files/covid_and_emplo yment_of_immigrants_june_2020.pdf

Burr, J. A., Mutchler, J. E., \& Gerst, K. (2010). Patterns of residential crowding among Hispanics in later life: Immigration, assimilation and housing market factors. The Journals of Gerontology Series B Psychological Sciences and Social Sciences, 65(6), 772-782. https://doi.org/10.1093/geronb/gbq069

Byrne, K. A., Kuttner, P., Mohamed, A., Reon Magana, G., \& Goldberg, E. E. (2018). This is our home: Initiating participatory action housing research with refugee and immigrant communities in a time of unwelcome. Action Research. https://doi.org/10.1177/ 2F1476750318790797

Calma, J. (2020, March 27). Migrants aren't to blame for COVID-19. The Verge. Retrieved from www.theverge.com/2020/3/27/21196 100/immigration-borders-covid-19-coronavirus 
Carson, L. R. (2009). “I am because we are:” Collectivism as a foundational characteristic of African American college student identity and academic achievement. Social Psychology of Education, 12(3), 327-344. https://doi.org/10.1007/s11218-009-9090-6

Center for Advanced Studies in Child Welfare. (2014). Somali Cultural Guide. Retrieved from: https://cascw.umn.edu/wp-content/uploa ds/2014/04/guides_somali.WEB_a.pdf

Centers for Disease Control (CDC). (2020). Temporary halt in residential evictions to prevent the further spread of COVID-19. Federal Register, 85(173). Retrieved from: https://www.federalregister. gov/documents/2020/09/04/2020-19654/temporary-halt-in-resid ential-evictions-to-prevent-the-further-spread-of-covid-19

Cholera, R., Falusi, O. O., \& Linton, J. M. (2020). Sheltering in place in a xenophobic climate: COVID-19 and children in immigrant families. Pediatrics. https://doi.org/10.1542/peds.2020-1094

Clark, E., Fredricks, K., Woc-Colburn, L., Bottazzi, M. E., \& Weatherhead, J. (2020). Disproportionate impact of the COVID-19 pandemic on immigrant communities in the United States. PLoS Neglected Tropical Diseases. https://doi.org/10.1371/journal.pntd. 0008484

Congressional Research Service. (2020). Demographic and social characteristics of persons in poverty: 2018. Retrieved from https:// fas.org/sgp/crs/misc/R46294.pdf

Culture Care Connection. (n.d.). Hispanic/Latino. Retrieved from https://culturecareconnection.org/cultural-responsiveness/hispa nic-latino/

Dearborn, L. M. (2008). Immigrant homeowners: Residential choices of low- and moderate- income Hmong in Milwaukee's central city. Journal of Architectural and Planning Research, 25(1), 25-41. https://www.jstor.org/stable/43030818

Desmond, M. (2018). Heavy is the house: Rent burden among the American urban poor. International Journal of Urban and Regional Research, 42(1), 160-170. https://doi.org/10.1111/ 1468-2427.12529

Domínguez, D. G., García, D., Martínez, D. A., \& Hernandez-Arriaga, B. (2020). Leveraging the power of mutual aid, coalitions, leadership, and advocacy during COVID-19. American Psychologist, 75(7), 909-918. https://doi.org/10.1037/amp0000693

Ebaugh, H. R., \& Currty, M. (2000). Fictive kin as social capital in new immigrant communities. Sociological Perspectives, 43, 189-209. https://doi.org/10.2307/1389793

Eisenberg, M. E., Puhl, R., Areba, E. M., \& Neumark-Sztainer, D. (2019). Family weight teasing, ethnicity and acculturation: Associations with well-being among Latinx, Hmong, and Somali Adolescents. Journal of Psychosomatic Research, 122, 88-93. https:// doi.org/10.1016/j.jpsychores.2019.04.007

Elo, S., \& Kyngäs, H. (2008). The qualitative content analysis process. Journal of Advanced Nursing, 62(1), 107-115. https://doi.org/10. 1111/j.1365-2648.2007.04569.x

Galea, S., Ahern, J., Resnick, H., Kilpatrick, D., Bucuvalas, M., Gold, J., \& Vlahov, D. (2002). Psychological sequelae of the September 11 terrorist attacks in New York City. New England Journal of Medicine, 346(13), 982-987. https://doi.org/10.1056/nejmsa0134 04

Garcini, L. M., Domenech Rodríguez, M. M., Mercado, A., \& Paris, M. (2020). A tale of two crises: The compounded effect of COVID-19 and anti-immigration policy in the United States. Psychological Trauma: Theory, Research, Practice, and Policy, 12, 2019-2021. https://doi.org/10.1037/tra0000775

Gil, R. M., Marcelin, J. R., Zuniga-Blanco, B., Marquez, C., Mathew, T., \& Piggott, D. A. (2020). COVID-19 pandemic: Disparate health impact on the Hispanic/Latinx population in the United States. Journal of Infectious Diseases, 15, 1592-1595. https://doi. org/10.1093/infdis/jiaa474

Hall, M., \& Greenman, E. (2013). Housing and neighborhood quality among undocumented Mexican and Central American immigrants. Social Science Research, 42, 1712-1725. https://doi. org/10.1016/j.ssresearch.2013.07.011

Hsieh, H.-F., \& Shannon, S. (2005). Three approaches to qualitative content analysis. Qualitative Health Research, 15, 1277-1288. https://doi.org/10.1177/1049732305276687

Karen Organization of Minnesota. (n.d.). Karen history. Retrieved from https://www.mnkaren.org/history-culture/karen-history/

Kerwin, D., \& Warren, R. (2020). US foreign-born workers in the global pandemic: Essential and marginalized. Journal on Migration and Human Security. https://doi.org/10.1177/2311502420 952752

Kim, H. N., Lan, K. F., Nkyekyer, E., Neme, S., Chew, L., \& Duber, H. C. (2020). Assessment of disparities in COVID-19 testing and infection across language groups in Seattle, Washington. JAMA Network Open. https://doi.org/10.1001/jamanetworkopen.2020. 21213

Kchhar, R. \& Bennett, J. (2021, July 26). Immigrants in U.S. experienced higher unemployment in the pandemic but have closed the gap. PEW Research Topics. Retrieved from: https://www.pewresearch.org/fact-tank/2021/07/26/immig rants-in-u-s-experienced-higher-unemployment-in-the-pande mic-but-have-closed-the-gap/

Kosten, D. (2018). Immigrants as economic contributors: They are the new American workforce. National Immigration Forum. Retrieved from https://immigrationforum.org/article/immig rants-as-economic-contributors-they-are-the-new-americanworkforce/

Levine, B. (2020). 2020: Report to the nation: Illustrated almanac. Center for the Study of Hate \& Extremism. Retrieved from https:// www.csusb.edu/sites/default/files/Special\%20Status\%20Report\% 20Nov\%202020\%2011.22.20\%20combined_0.pdf

Mattar, S., \& Piwowarczyk, L. A. (2020). COVID-19 and U.S.-based refugee populations: Commentary. Psychological Trauma: Theory, Research, Practice, and Policy, 12, 228-229. https://doi.org/ $10.1037 /$ tra0000602

McKinney-Vento Homelessness Assistance Act §11434a. (2002). Retrieved from https://uscode.house.gov/view.xhtml?path=/prelim@title42/chapter119/subchapter6/partB\&edition=prelim

McConnell, E. D. (2013). Who has housing affordability problems? Disparities in housing cost burden by race, nativity, and legal status in Los Angeles. Race and Social Problems, 5(3), 173-190. https://doi.org/10.1007/s12552-013-9086-x

McConnell, E. D. (2017). Rented, crowded, and unaffordable? Social vulnerabilities and the accumulation of precarious housing conditions in Los Angeles. Housing Policy Debate, 27(1), 60-79. https://doi.org/10.1080/10511482.2016.1164738

McCue, D. (2018). Digging deeper: Ten striking findings from our latest state of the nation's housing report. Joint Center for Housing Studies of Harvard University. Retrieved from: https://www.jchs. harvard.edu/blog/digging-deeper-ten-striking-findings-from-ourlatest-state-of-the-nations-housing-report/

Morrow, S. L. (2005). Quality and trustworthiness in qualitative research in counseling psychology. Journal of Counseling Psychology, 52, 250-260. https://doi.org/10.1037/0022-0167.52.2. 250

O'Donnell, A. W., Stuart, J., \& O'Donnell, K. J. (2020). The long-term financial and psychological resettlement outcomes of pre-migration trauma and post-settlement difficulties in resettled refugees. Social Science \& Medicine, 262, 113246-113255. https://doi.org/ 10.1016/j.socscimed.2020.113246

Page, K. R., \& Flores-Miller, A. (2021). Lessons we've learnedCovid-19 and the undocumented Latinx community. New England Journal of Medicine, 384(1), 5-7. https://doi.org/10.1056/ NEJMp2024897 
Page, K. R., Venkataramani, M., Beyrer, C., \& Polk, S. (2020). Undocumented U.S. immigrants and Covid-19. New England Journal of Medicine, 382(21), e62. https://doi.org/10.1056/NEJMp2005953

Patterson, J. M. (1988). Families experiencing stress: I. The family adjustment and adaptation response model: II. Applying the FAAR Model to health-related issues for intervention and research. Family Systems Medicine, 6(2), 202-237. https://doi. org/10.1037/h0089739

Perreira, K. M., Yoshikawa, H., \& Oberlander, J. (2018). A new threat to immigrants' health-The public-charge rule. New England Journal of Medicine, 379(10), 901-903. https://doi.org/10.1056/ nejmp1808020

Pew Research Center. (2011). Demographics of multi-generational households. In fighting poverty in a bad economy, Americans move in with relatives. Retrieved from https://www.pewresearch. org/social-trends/2011/10/03/chapter-3-demographics-of-multigenerational-households/\#native-born-and-foreign-born

Power, D. V., Moody, E., Trussell, K., O'Fallon, A., Chute, S., Kyaw, M., Letts, J., \& Mamo, B. (2010). Caring for the Karen A newly arrived refugee group. Minnesota Medicine, 93(4), 49-53.

Ranard, D. A., \& Barron, S. (2007). Refugees from Burma: Their backgrounds and refugee experiences. Center for Applied Linguistics: Cultural Profiles, 21. Retrieved from: http://www.culturalorienta tion.net

Sanon, M.-A., Spigner, C., \& McCullagh, M. C. (2016). Transnationalism and hypertension self-management among Haitian immigrants. Journal of Transcultural Nursing, 27(2), 147-156. https:// doi.org/10.1177/1043659614543476

Smets, K. (2018). The way Syrian refugees in Turkey use media: Understanding connected refugees; through a non-media-centric and local approach. Communications, 43(1), 113-123. https://doi. org/10.1515/commun-2017-0041

Tran, V. C., \& Francisco, L.-G. (2020). A new beginning: Early refugee integration in the United States. The Russell Sage Foundation Journal of the Social Sciences, 6(3), 117-149. https://doi.org/10. 7758/RSF.2020.6.3.06

U.S. Bureau of Labor Statistics. (2018a). Labor force characteristics by race and ethnicity, 2018. Retrieved from https://www.bls.gov/ opub/reports/race-and-ethnicity/2018/home.htm

U.S. Bureau of Labor Statistics. (2018b). Workers who could work at home, did work at home, and were paid for work at home, by selected characteristics, averages for the period 2017-2018. Retrieved from https://www.bls.gov/news.release/flex2.t01.htm
U.S. Bureau of Labor Statistics. (2020). Labor force characteristics of foreign-born workers news release. Retrieved from https://www. bls.gov/news.release/forbrn.htm

van Gelder, N., Peterman, A., Potts, A., O'Donnell, M., Thompson, K., Shah, N., \& Oertelt-Prigione, S. (2020). COVID-19: Reducing the risk of infection might increase the risk of intimate partner violence. EClinicalMedicine, 21, 1-2. https://doi.org/10.1016/j. eclinm.2020.100348

Vesely, C. K., Letiecq, B. L., \& Goodman, R. D. (2017). Immigrant family resilience in context: Using a community-based approach to build a new conceptual model. Journal of Family Theory \& Review, 9(1), 93-110. https://doi.org/10.1111/jftr.12177

Weng, S. S., \& Lee, J. S. (2016). Why do immigrants and refugees give back to their communities and what can we learn from their civic engagement? VOLUNTAS: International Journal of Voluntary and Nonprofit Organizations, 27(2), 509-524. https://doi.org/10.1007/ s11266-015-9636-5.pdf

Wilmsen, B. (2013). Family separation and the impacts on refugee settlement in Australia. Australian Journal of Social Issues, 48(2), 241-262. https://doi.org/10.1002/j.1839-4655.2013.tb00280.x

Wilson, F. A., \& Stimpson, J. P. (2020). US policies increase vulnerability of immigrant communities to the COVID-19 pandemic. Annals of Global Health, 86(1), 1-2. https://doi.org/10.5334/ aogh.2897

Yoshikawa, H., Wuermli, A. J., Britto, P. R., Dreyer, B., Leckman, J. F., Lye, S. J., Ponguta, L. A., Richter, L. M., \& Stein, A. (2020). Effects of the global coronavirus disease-2019 pandemic on early childhood development: Short- and long-term risks and mitigating program and policy actions. The Journal of Pediatrics, 223, 188-193. https://doi.org/10.1016/j.jpeds.2020.05.020

Zhou, M., \& Xiong, Y. S. (2005). The multifaceted American experiences of the children of Asian immigrants: Lessons for segmented assimilation. Ethnic and Racial Studies, 28(6), 1119-11152. https://doi.org/10.1080/01419870500224455

Publisher's Note Springer Nature remains neutral with regard to jurisdictional claims in published maps and institutional affiliations. 